\title{
Head impacts in a junior rugby league team measured with a wireless head impact sensor: an exploratory analysis
}

\author{
Doug King, PhD, ${ }^{1}$ Patria Hume, PhD, ${ }^{1}$ Conor Gissane, $\mathrm{PhD},{ }^{2}$ and Trevor Clark, $\mathrm{MSc}^{3}$ \\ 1Sports Performance Research Institute New Zealand, Faculty of Health and Environmental Science, Auckland University \\ of Technology, Auckland, New Zealand; ' 2 School of Sport Health and Applied Science, St Mary's University, Twickenham, \\ Middlesex, United Kingdom; and ${ }^{3}$ Australian College of Physical Education, Faculty of Sport Performance, Sydney Olympic Park, \\ New South Wales, Australia
}

OBJECTIVE The aim of this study was to investigate the frequency, magnitude, and distribution of head impacts sustained by players in a junior rugby league over a season of matches.

METHODS The authors performed a prospective cohort analysis of impact magnitude, frequency, and distribution on data collected with instrumented XPatches worn behind the ear of players in an "under-11" junior rugby league team (players under 11 years old).

RESULTS A total of 1977 impacts were recorded. Over the course of the study, players sustained an average of 116 impacts (average of $13 \mathrm{impacts}$ per player per match). The measured linear acceleration ranged from $10 \mathrm{~g}$ to $123 \mathrm{~g}$ (mean $22 \mathrm{~g}$, median $16 \mathrm{~g}$, and 95 th percentile $57 \mathrm{~g}$ ). The rotational acceleration ranged from $89 \mathrm{rad} / \mathrm{sec}^{2}$ to $22,928 \mathrm{rad} / \mathrm{sec}^{2}$ (mean $4041 \mathrm{rad} / \mathrm{sec}^{2}$, median $2773 \mathrm{rad} / \mathrm{sec}^{2}$, and 95 th percentile 11,384 rad $\left./ \mathrm{sec}^{2}\right)$.

CONCLUSIONS The level of impact severity based on the magnitude of impacts for linear and rotational accelerations recorded was similar to the impacts reported in studies of American junior and high school football, collegiate football, and youth ice hockey players, but the players in the rugby league cohort were younger, had less body mass, and played at a slower speed than the American players. Junior rugby league players are required to tackle the player to the ground and use a different tackle technique than that used in American football, likely increasing the rotational accelerations recorded at the head.

http://thejns.org/doi/abs/10.3171/2016.7.PEDS1684

KEY WORDS injury; linear; rotational; impact; rugby union; wireless head impact sensor; trauma

$\mathrm{T}$ HE increasing media-and public-awareness of sports-related concussion in regard to the concern for player safety and the risk of injury ${ }^{7,11,48}$ has been accompanied by an increase in knowledge about the potential structural and metabolic consequences of impacts to the head. As a result there is an increased appreciation for repetitive concussive, and subconcussive, impacts and the possible deleterious effects in some individuals. ${ }^{48}$ The utilization of accelerometers worn in helmets of American football players ${ }^{5,10,11}$ for the analysis of head impact injury biomechanics has assisted in increasing our knowledge of the velocities, forces, accelerations, and frequency of head injuries. ${ }^{30,48}$ The information that has been acquired from conducting this analysis can be applied to circumstances where head impact injuries can occur.

It has been reported ${ }^{31,48}$ that youth football players may not incur any meaningful impacts to the head because compared with adults they are smaller, have a lower impact velocity, and participate less in sporting activities. Despite these factors, however, the risks of concussions and prolonged recovery from such injuries ${ }^{14}$ occurring from participation in sporting activities such as rugby union ${ }^{26,30}$ and American football ${ }^{11,12,48}$ are higher in younger players. ${ }^{12}$ Although youth players are smaller and have fewer recorded head impacts than older players, their recorded impacts are high-magnitude impacts..$^{11,30,48}$ In our previous

ABBREVIATIONS HITS = Head Impact Telemetry System; HIT $=$ Head Impact Telemetry severity profile; ICC = intraclass correlation coefficient; ImPACT = Immediate Postconcussion Assessment Cognitive Test; K-D = King-Devick; NFL = National Football League; PLA = peak linear acceleration; PRA peak rotational acceleration; RWE $=$ risk weighted exposure based on combined probability. SUBMITTED February 12, 2016. ACCEPTED July 20, 2016.

INCLUDE WHEN CITING Published online October 28, 2016; DOI: 10.3171/2016.7.PEDS1684. 
study on junior rugby union players under 9 years of age, ${ }^{30}$ 721 impacts to the head were recorded with median linear and rotational accelerations of $15 \mathrm{~g}$ and $2296 \mathrm{rad} / \mathrm{sec}^{2}$. In a study of 7- and 8-year-old children playing youth (6-9 years old) American football,,$^{11}$ an average of 107 impacts per player per season were recorded, with average linear and rotational accelerations of $18 \mathrm{~g}$ and $901 \mathrm{rad} / \mathrm{sec}^{2}$. In a group of slightly older players (Pop Warner "Junior Midgets" football players 12-13 years of age), there were 480 impacts recorded during matches, with an average linear acceleration of $47 g \pm 14 g .{ }^{48}$ This average linear acceleration value was higher than the match median value of $21 \mathrm{~g}$ $\pm 3 g$ reported for a group of middle school football players with a similar age range (12-14 years). ${ }^{12}$ The long-term implications of these high-magnitude impacts to young players in an exposure paradigm are unknown. ${ }^{48}$

Accelerometers have also been used in nonhelmeted sports for measuring impacts from sports participation. In a study of female youth soccer players, heading the ball yielded peak accelerations of $63 \mathrm{~g}$ (linear) and $8869 \mathrm{rad} /$ $\sec ^{2}$ (rotational). ${ }^{22}$ Injury risk was assessed and no concussions were recorded, but some of the rotational accelerations were within the nominal values for an injury to the head when compared with US National Football League (NFL) data ${ }^{41}$ and injury risk tolerance levels. ${ }^{51}$ Although head impact data are accumulating for soccer and the NFL, there are no published data for nonhelmeted collision sports such as rugby league.

In a previous study, ${ }^{30}$ we investigated the frequency, magnitude, and distribution of head impacts sustained by junior under-9-year-old rugby union players in New Zealand during 4 matches. An identical approach was undertaken in the current study, but this time we investigated head impacts in junior under-11-year-old rugby league players and analyzed data from a full season of competition matches.

\section{Methods}

A prospective observational study was conducted in a junior club level rugby league team during the 2014 competition season in New Zealand. Nineteen players (14 boys and 5 girls) were enrolled in the study. The participants' mean $( \pm \mathrm{SD})$ age, body mass, and height were $10 \pm 1$ years, $55 \pm 17 \mathrm{~kg}$, and $1.5 \pm 0.1 \mathrm{~m}$, respectively. Consent was obtained from the players' parents or guardians prior to enrollment. The Auckland University of Technology ethics committee approved all procedures in the study. The methods used in this study were identical to those used in our previous study of head impact acceleration in junior rugby union team players. ${ }^{30}$

All players enrolled in the study wore the XPatch impact-sensing skin patch (X2Biosystems Inc.) on the skin covering their right-side mastoid process for each match. The XPatch sensor, sampling at $1024 \mathrm{~Hz}$, was placed behind the player's right ear just before participation in match activities and was removed immediately after completion of the match. The positioning of the XPatch over the mastoid process ensured that the sensor was not activated by enhanced soft-tissue effects when impacts occurred. ${ }^{49}$

The XPatch contains a low-power, high-g triaxial ac- celerometer with a $200 \mathrm{~g}$ maximum per axis and a triaxial angular rate gyroscope. This enables capture of 6 degrees of freedom for linear and rotational time history accelerations of the head's center of gravity for all impacts that occur during match participation. The time history incorporated 3 axes $(\mathrm{x}=$ medial-lateral, $\mathrm{y}=$ anterior-posterior, $\mathrm{Z}=$ vertical) of acceleration/deceleration and 3 axes of velocity.

The XPatch was shown in one study ${ }^{38}$ to have good agreement with peak linear acceleration (PLA) but was found to underestimate peak rotational acceleration (PRA) by more than $25 \%$. In another study ${ }^{49}$ it was reported that the XPatch has a strong correlation for peak linear accelerations (PLA, $\mathrm{r}^{2}=0.93$ ), with a normalized root square error of $18 \%$, but may overpredict PLA and peak rotational accelerations (PRA) by $15 g \pm 7 g$ and $2500 \pm 1200 \mathrm{rad} /$ $\mathrm{sec}^{2}$, respectively. It has been reported ${ }^{33}$ that the XPatch has statistically significant correlations with the Head Impact Telemetry System (HITS, Riddell) for resultant linear $(\mathrm{r}=0.44, \mathrm{p}<0.001)$ and rotational $(\mathrm{r}=0.15, \mathrm{p}<0.001)$ accelerations and for the Head Impact Telemetry severity profile $\left(\mathrm{HIT}_{\mathrm{SP}}\right)(\mathrm{r}=0.34, \mathrm{p}<0.0001)$. A total of $100 \mathrm{msec}$ of data (10 msec pretrigger and $90 \mathrm{msec}$ posttrigger) from each accelerometer and gyroscope were recorded to the on-board memory for later downloading if an accelerometer exceeded the predetermined $10 \mathrm{~g}$ linear acceleration threshold. This data acquisition threshold was based on a review of data acquisition thresholds used in previously published studies. ${ }^{29}$

The XPatch was removed from each player and the data were downloaded to the X2Biosystems injury management software following the match. The software enabled the raw accelerometer data to be transformed to the head center of gravity by using a rigid-body transformation for linear acceleration and a 5-point stencil for rotational acceleration. ${ }^{29,49}$ Biomechanical measures of head impact severity consisted of impact duration (msec) and linear $(g)$ and rotational head acceleration $\left(\mathrm{rad} / \mathrm{sec}^{2}\right)$. Resultant linear acceleration is the rate of change in velocity of the estimated center of gravity of the head attributable to an impact and the associated direction of motion of the head. ${ }^{37} \mathrm{Re}-$ sultant rotational acceleration is the rate of change in rotational velocity of the head attributable to an impact and its direction in a coordinate system with the origin at the estimated center of gravity of the head. ${ }^{37}$ False impacts were removed by the X2Biosystems proprietary "de-clacking" algorithm ${ }^{29}$ by comparing the waveform of each impact to a "Gaussian-like" reference waveform using cross-correlation. ${ }^{29}$ Impact data were downloaded to an Excel spreadsheet and time-filtered to include only data from impacts that occurred during match participation.

Head impact exposure data, including frequency, magnitude, and location of impacts, were quantified using previously established methods. ${ }^{9,10}$ Data collection was delimited to matches only-not team training sessions. Three measures of impact frequency were computed: 1) player position impacts, the total and average number of head impacts recorded for the playing position for all matches; 2) player group impacts, the total and average number of recorded head impacts for the playing group (hit-up forward, adjustables, and outside backs) for all matches; and 3) impacts per match, the total and average number of impacts 
per match for all matches. Due to the age of the players and ethical considerations, video capture was not conducted on the matches; therefore verification of the impacts in conjunction with video evidence was not possible.

All filtered data on the Microsoft Excel spreadsheet were analyzed with SPSS version 22.0.0. The impact variables were not normally distributed (Kolmogorov-Smirnov, $\mathrm{p}<$ $0.001)$. Therefore data for these variables were expressed as median [IQR], and as severity measures (95th percentile linear acceleration, 95th percentile rotational acceleration). ${ }^{24,25}$ Additionally the cumulative impact burden per match competition and per player per match were analyzed using a Kruskal-Wallis 1-way ANOVA with a Dunn post hoc test for all pairwise comparisons. Although there is no accepted method to quantify cumulative impact burden, ${ }^{2}$ the sum of linear and rotational accelerations associated with each individual head impact over the course of the study were calculated for all of these parameters.

The impact location variables were computed as azimuth and elevation angles relative to the center of gravity of the head centered on the midsagittal plane. ${ }^{8}$ These were categorized as front (left: $\theta=180^{\circ}$ to $-135^{\circ}$; right: $\theta=180^{\circ}$ to $135^{\circ}$ ), side (left: $\theta=-135^{\circ}$ to $-45^{\circ}$; right: $\theta=$ $135^{\circ}$ to $45^{\circ}$ ), back (left: $\theta=-45^{\circ}$ to $0^{\circ}$; right: $\theta=45^{\circ}$ to $0^{\circ}$ ) and top (left: $\theta=180^{\circ}$ through negative $\theta$ to $0^{\circ}$; right: $\theta=180^{\circ}$ through positive $\theta$ to $0^{\circ}$ ). Impacts to the top of the head were defined as all impacts above an $\alpha$ of $65^{\circ}$ from a horizontal plane through the center of gravity of the head. ${ }^{20}$ Impact locations were analyzed by front, back, side, and top impacts using a Friedman repeated measures ANOVA on ranks.

Head impacts were assessed for injury tolerance level for a concussion occurring, using previously published injury tolerance levels ${ }^{2,4,21}$ for linear $(>95 g)$ and rotational acceleration $\left(>5500 \mathrm{rad} / \mathrm{sec}^{2}\right)$. Head impacts were assessed for impact severity, using previously published levels for linear acceleration (mild, < 66g; moderate, $66 g-106 g$; and severe, $>106 \mathrm{~g}$ ) and rotational acceleration (mild, < 4600 $\mathrm{rad} / \mathrm{sec}^{2}$; moderate, 4600-7900 $\mathrm{rad} / \mathrm{sec}^{2}$; and severe, $>$ $\left.7900 \mathrm{rad} / \mathrm{sec}^{2}\right) .^{23,39,51}$

Two additional risk equations were included in the analysis of the impact data to identify players at risk of a concussion. The Head Impact Telemetry severity profile $\left(\mathrm{HIT}_{\mathrm{SP}}\right)^{20}$ is a weighted composite score that includes linear and rotational accelerations and impact duration, as well as impact location. The risk weighted exposure based on combined probability $\left(\mathrm{RWE}_{\mathrm{CP}}\right)^{46}$ incorporates a logistic regression equation and a regression coefficient based on previously published analytical risk functions for analyzing the combined contributions of linear and rotational accelerations to individual player and team-based exposure to head impacts. As a value of 63 is a $75 \%$ indicator for a concussive injury, ${ }^{3,20}$ the $\mathrm{HIT}_{\mathrm{SP}}$ values were evaluated by limits of less than $25 \%$ risk $(<21), 25 \%-75 \%$ risk $(21-63)$, and $>75 \%$ risk $(>63)$. The $\mathrm{RWE}_{\mathrm{CP}}$ values were assessed with the same percentage indicators of $25 \%$ risk $(<0.2500)$, $25 \%-75 \%$ risk $(0.2500-0.7500)$, and $>75 \%$ risk $(>0.7500)$. The $\mathrm{HIT}_{\mathrm{SP}}$ and $\mathrm{RWE}_{\mathrm{CP}}$ were analyzed according to player position by total, forwards', outside backs', and adjustables' impacts using a Friedman repeated-measures ANOVA on ranks. Post hoc analysis with Wilcoxon signed-rank tests was conducted with a Bonferroni correction applied. A 1-sample chi-square test with $95 \%$ confidence intervals was used to determine whether the observed impact frequency was significantly different from the expected impact frequency. Statistical significance was set at $\mathrm{p}<$ 0.05 . Our results were then compared with those for studies quantifying head impact exposure in American junior and high school football, collegiate football, and youth ice hockey players and New Zealand senior amateur rugby union players.

Prior to the first match the players completed a baseline King-Devick (K-D) test using 2 of the 3 test cards. The K-D test is a rapid number naming test that takes less than 2 minutes to administer. ${ }^{16,17}$ The test involves having the player read a random series of single-digit numbers aloud from left to right on 3 test cards. The K-D test includes 1 practice (demonstration) card and test cards varied in format on a moisture-proof $6 \times 8$-inch spiral-bound physical test booklet or as an application on an iPad platform. The K-D tests used were version 2.2.0 (http://www. kingdevicktest.com) on an iPad2 (Apple). The iPad2 testing platform enables the use of the K-D test with 3 different number-set test versions, and these were varied over the duration of the study to reduce possible learning effects. Time was kept for each test card, and the K-D test summary score for the entire test was based on the cumulative time taken to read all 3 test cards. The number of errors made in reading the test cards was also recorded. The best time (fastest) of the 2 trials without errors became the established baseline K-D test time. ${ }^{16}$

During matches, players were observed by the researcher for any signs of a direct blow to the head, for being slow to rise from a tackle or collision, or for being unsteady on their feet following a collision or tackle. If any such signs were observed, the player was removed from the match activity by the team coach and rested on the sideline. In addition, the player's parents would bring their child to the tester to undertake the K-D test evaluation following any incident they considered to be an impact to their child's head. Players who reported any sign(s) of a concussion, who were suspected to have received a concussive injury, or who were removed from match participation were assessed with the K-D test on the sideline after a 10-minute rest period; were not allowed to return to play on the same day; and were referred for further medical assessment. The postmatch administration of the K-D test was performed using the same instructions as for the baseline evaluation, and the time and errors made were recorded and compared with the participant's baseline. No player identified with delayed (worsening) postmatch K-D times was allowed to return to training or match activities without a full medical clearance. The procedures used for identification, assessment, and management of players identified with a suspected concussive injury were identical to those used in a previous study ${ }^{27}$ No player who was identified with a delay (worsening) of the K-D test and referred to his or her health professional was immediately cleared for return to play. No player was allowed to return to full match activities until he or she was medically cleared and the K-D score had returned to the baseline value. All players were tested again at the end of the competition season to determine 
whether any changes had occurred from the beginning of the season.

The K-D test has been reported to have interclass correlation coefficients (ICCs) for test-retest reliability of $0.96^{34}$ and $0.97 . .^{16}$ The test has also been reported to have significant correlations $(\mathrm{p}<0.0001)$ with the visual motor speed, reaction time, verbal memory, and visual memory assessments of the Immediate Postconcussion Assessment Cognitive Test (ImPACT) ${ }^{45}$ computerized concussion evaluation system.

All K-D test data collected were entered into a Microsoft Excel spreadsheet and analyzed with IBM SPSS Statistics for Windows version 22.0.0. Data are presented as mean $( \pm$ SD) for player data, concussive injury per 1000 match hours with $95 \%$ confidence interval, and median [IQR] for K-D scores. Differences in K-D scores from precompetition (baseline establishment) were calculated; baseline and postmatch K-D scores were compared using the Wilcoxon signed-rank test by the sporting code and as a combined composite score. The sensitivity and specificity of the K-D test were calculated using a 2-by-2 contingency table (with 95\% CIs). ${ }^{1,32}$ Test-retest reliability was also estimated utilizing the ICC, with $95 \%$ confidence intervals, to examine agreement between first and second baseline test scores and the poststudy scores.

\section{Results}

Twelve matches were completed over the competition season, giving a match exposure of 88.0 hours. Both linear and rotational accelerations were right skewed and heavily weighted toward low-magnitude impacts for impacts greater than the data acquisition thresholds used. Resultant linear accelerations ranged from $10 \mathrm{~g}$ to $123 \mathrm{~g}$ (mean $22 \mathrm{~g}$, median $16 g$, 95th percentile $57 g$ ). Resultant rotational accelerations ranged from 89 to $22,928 \mathrm{rad} / \mathrm{sec}^{2}$ (mean 4041 $\mathrm{rad} / \mathrm{sec}^{2}$, median $2773 \mathrm{rad} / \mathrm{sec}^{2}$, 95th percentile 11,384 rad/ $\left.\sec ^{2}\right)$.

Overall, 1977 impacts over the data acquisition thresholds were recorded for the match competition season (Table 1). Each player experienced a mean of 116 impacts per player over the duration of the match season and a mean of 13 impacts over the $10 \mathrm{~g}$ threshold per player per match. Although more impacts were recorded for forwards than for backs (1511 vs 466, $\mathrm{p}<0.001$ ) over the duration of the match season, the average resultant linear ( $23 g$ vs $22 g$, p $=0.728)$ and resultant rotational (4534 vs $3889 \mathrm{rad} / \mathrm{sec}^{2}$, $\mathrm{p}=0.539$ ) accelerations were higher for backs than for forwards.

More impacts were recorded to the side of the head (48\% of impacts $>10 \mathrm{~g})$ than the front $(26 \%, \mathrm{p}<0.0001)$, back $(25 \%, \mathrm{p}<0.0001)$, or top $(1 \%, \mathrm{p}<0.0001)$ of the head (Table 2). The proportion of impacts recorded to the side of the head was greater for forwards than for backs $(50 \%$ vs $39 \%, \mathrm{p}=0.0031$ ). The median resultant rotational acceleration recorded for the top of the head was higher than that recorded for the side of the head $\left(6104 \mathrm{rad} / \mathrm{sec}^{2}\right.$ [IQR $3603-10,796 \mathrm{rad} / \mathrm{sec}^{2}$ ] vs $2161 \mathrm{rad} / \mathrm{sec}^{2}$ [IQR 1409-5586 $\left.\left.\mathrm{rad} / \mathrm{sec}^{2}\right], \mathrm{p}=0.0007\right)$. Although forwards had a greater proportion of impacts recorded for the back of the head $(26 \%)$ than did backs $(22 \%, \mathrm{p}<0.0001)$, the backs had

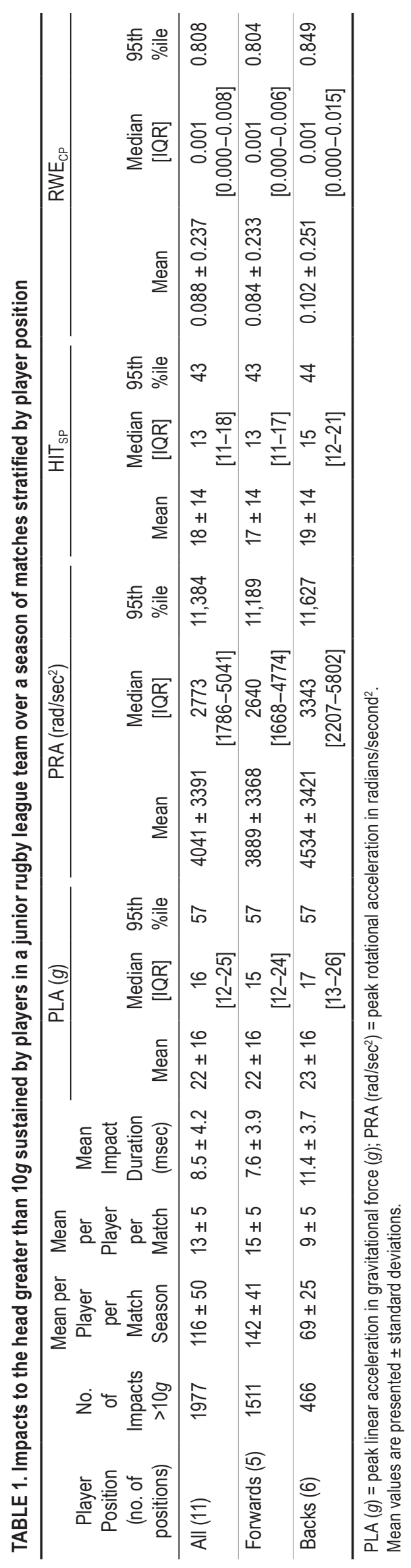




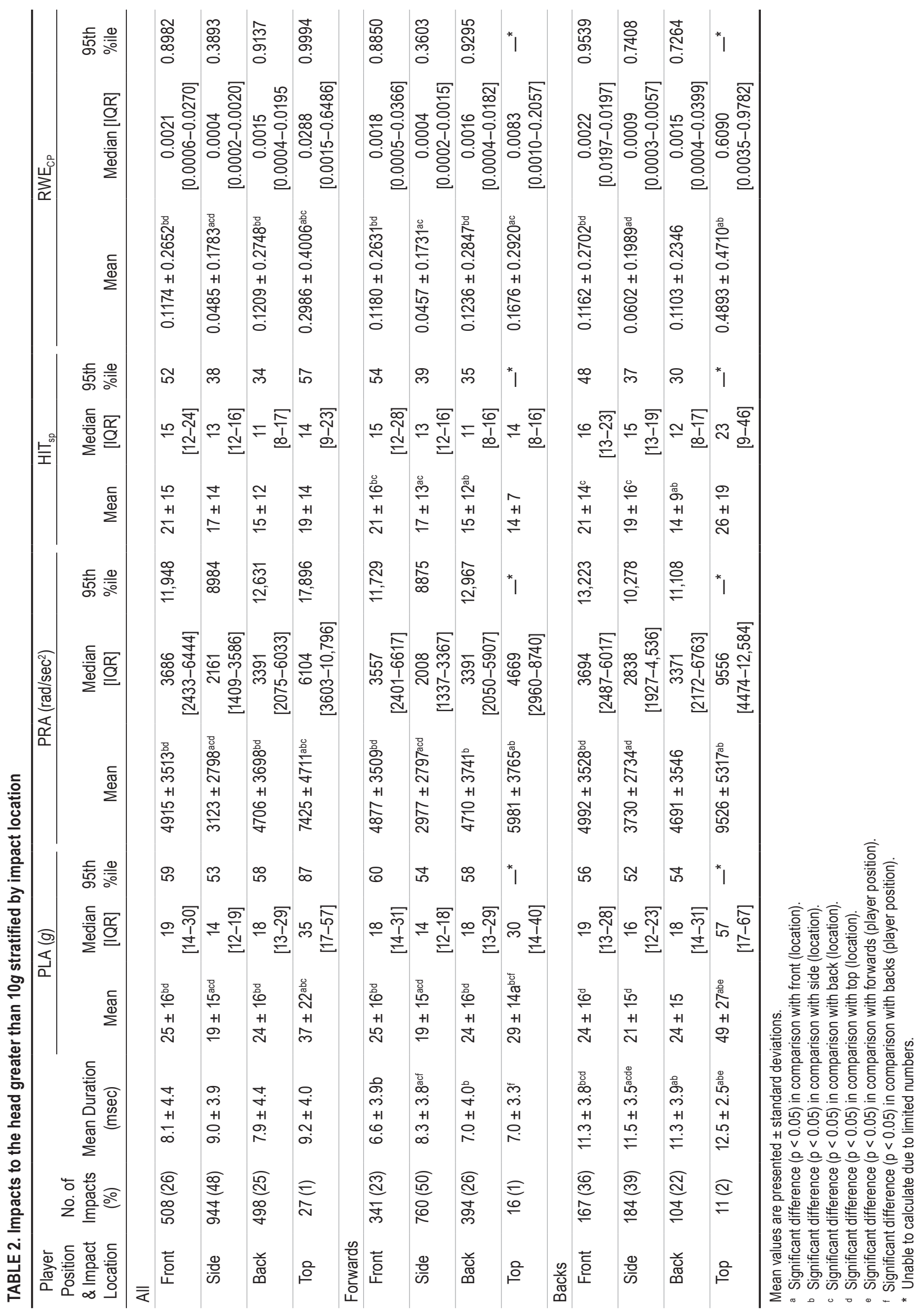


a higher median linear acceleration to the back of the head than forwards $(57 g[17 g-67 g]$ vs $30 g[14 g-40 g]$, $\mathrm{p}=$ 0.0021).

A total of $10(0.5 \%)$ of the recorded impacts were above the linear tolerance threshold $(>95 \mathrm{~g}$ ), and the median resultant impact for these instances was $105 g$ (IQR $101 g-108 g$ ) (Table 3). Analysis of this subset of 10 impacts above the linear $(>95 g)$ injury tolerance showed that for these impacts, forwards recorded higher median linear accelerations than backs (104g [IQR $101 g-106 g$ ] vs $103 g$ [IQR $98 g-123 g], \mathrm{p}=0.564)$. The majority of linear impacts were under the low injury severity threshold $(97 \%$ of total impacts, $97 \%$ of impacts sustained by forwards, and $97 \%$ of impacts sustained by backs). The mean recorded impact duration was longer for backs than for forwards (11.4 vs 7.6 seconds, $\mathrm{p}<0.0001)$ for all impacts under the low linear injury severity threshold $(<66 g)$. The proportion of recorded impacts that were in the moderate severity range for $\mathrm{HIT}_{\mathrm{SP}}$ values (21-63) was greater for backs than for forwards $(22 \%$ vs $15 \%, \mathrm{p}=0.0013)$. As a result, the median $\mathrm{RWE}_{\mathrm{CP}}$ value for impacts in the moderate severity range $(0.2500-0.7500)$ was greater for backs than for forwards $(0.5142$ [IQR $0.4034-0.6823$ ] vs 0.4425 [IQR $0.3390-0.6276], \mathrm{p}<0.0001)$. Although only $2 \%$ of impacts recorded were over the severe impact threshold for $\mathrm{HIT}_{\mathrm{SP}}$ $(>63), 6 \%$ of recorded impacts had an $\mathrm{RWE}_{\mathrm{CP}}$ value that was over the severe threshold (0.7500).

There were observable learning effects between the first and second K-D tests during the baseline testing ( 66.8 vs 63.1 seconds, $\mathrm{z}=2.97, \mathrm{p}=0.0015$ ) as well as between the baseline and poststudy tests (62.1 vs 51.4 seconds, $\mathrm{z}=$ $3.81, \mathrm{p}<0.0001)$ (Table 4). No concussions were observed on the field over the duration of the study. Postmatch K-D testing identified 6 players as having had a delay (worsening) of more than 3 seconds from their baseline K-D score times (median delay 4.9 seconds [IQR 3.6-6.4 seconds] $(\mathrm{z}=-2.37, \mathrm{p}=0.018)$ (Table 5); one of these players had 2 delays in postmatch scores. Thus a total of 7 concussions were identified. The K-D test had a sensitivity of 1.00 (95\% CI 0.73-1.00) and a specificity of 0.85 (95\% CI 0.42-0.97).

\section{Discussion}

This study reports, for the first time, the head impact biomechanics experienced during 12 competition matches by a team of junior rugby league players under the age of 11 years. High-magnitude impacts (> 80g) were experienced by this cohort during match participation. This level of severity was similar to that of impacts reported in American high school ${ }^{4-6}$ and collegiate ${ }^{6,9,10}$ football, but the New Zealand rugby league players were younger, had less body mass, and played at a slower speed than the American players. ${ }^{11,50}$ Rugby league players do not wear the same protective equipment as American football players.

It has been reported ${ }^{18}$ that worsening of the K-D test is likely to reflect the anatomical aspects captured by the test. Pathways for saccades are widely distributed, involving several areas of the brain and incorporating frontal eye fields, supplementary eye fields, dorsolateral prefrontal cortex, parietal lobes, and deeper structures such as the brainstem, necessitating the involvement of several cortical areas in the production, and regulation, of these rapid eye movements. ${ }^{18}$ Saccades can be used to assess cognitive domains such as attention, spatial and temporal orientation, and working memory. ${ }^{18,42}$ These assessments need to be both fast and accurate to effectively acquire image information in real time and are particularly demanding for the brain. ${ }^{18,42}$ Injuries resulting in the disruption of areas involved in saccade production and regulation can result in changes in these cognitive domains. ${ }^{18}$ The K-D test enables the analysis of numerous circuits throughout the brain involved in motivation, visuospatial integration, attention, motor planning, and spatial organization..$^{13}$ The test requires the utilization of saccades and may also reflect concentration and language function. ${ }^{18}$ Injuries to any of the areas involved in saccade production and regulation may explain the eye movement- and memory-related problems that can occur following a concussive injury. ${ }^{18}$

In line with the previous guidelines for the use of the $\mathrm{K}-\mathrm{D}$ test, ${ }^{28}$ players who had a delay (worsening) in their test performance were not allowed to participate in the rest of the match. Their parents were advised to have their child examined medically for a concussive injury. All identified players with delayed K-D test results underwent assessment by a qualified health care practitioner, were determined to have sustained a concussive injury (Table 5), and subsequently followed a medically supervised returnto-sport graduated stepwise protocol. ${ }^{28}$ Initially none of these players were observed to have any visible signs of concussion while participating in match activities, and the parents watching did not report having any concern for a possible concussive injury. After 3 players showed postmatch delays from baseline test scores, however, and were subsequently identified medically as having a concussive injury, the parents at the matches became more vigilant, and in the cases of Players 5 and 6, the parents asked for the players to be removed from the matches and requested assessment with the K-D test. These 2 players were both assessed as having a concussive injury, with Player 6 having a delay of 23 seconds from his baseline K-D score. Player 1 was removed from any further match or training participation for the remainder of the season after the second concussive injury.

Comparison of impact data from study to study can be difficult due to the different thresholds used to record an impact and the different sporting activities involved. For example, the data acquisition limit used for the recording of impacts to the head in youth American football have varied, with different studies reporting $10 g,{ }^{11} 14.4 g, 712,49$ and $30 g{ }^{48}$ As a result of these differences, interstudy comparisons are limited unless the data are stratified by the different impact thresholds, necessitating multiple complex tables. Although data from these studies were included for comparison with the current study, caution in interpretation is needed, given that we reported the data utilizing a $10 g$ data acquisition threshold.

The number of impacts recorded for different age groups has also varied. Recording of impacts to the head in youth American football players aged 7-8 years showed an average of 44 impacts per match or 5.8 impacts per player 


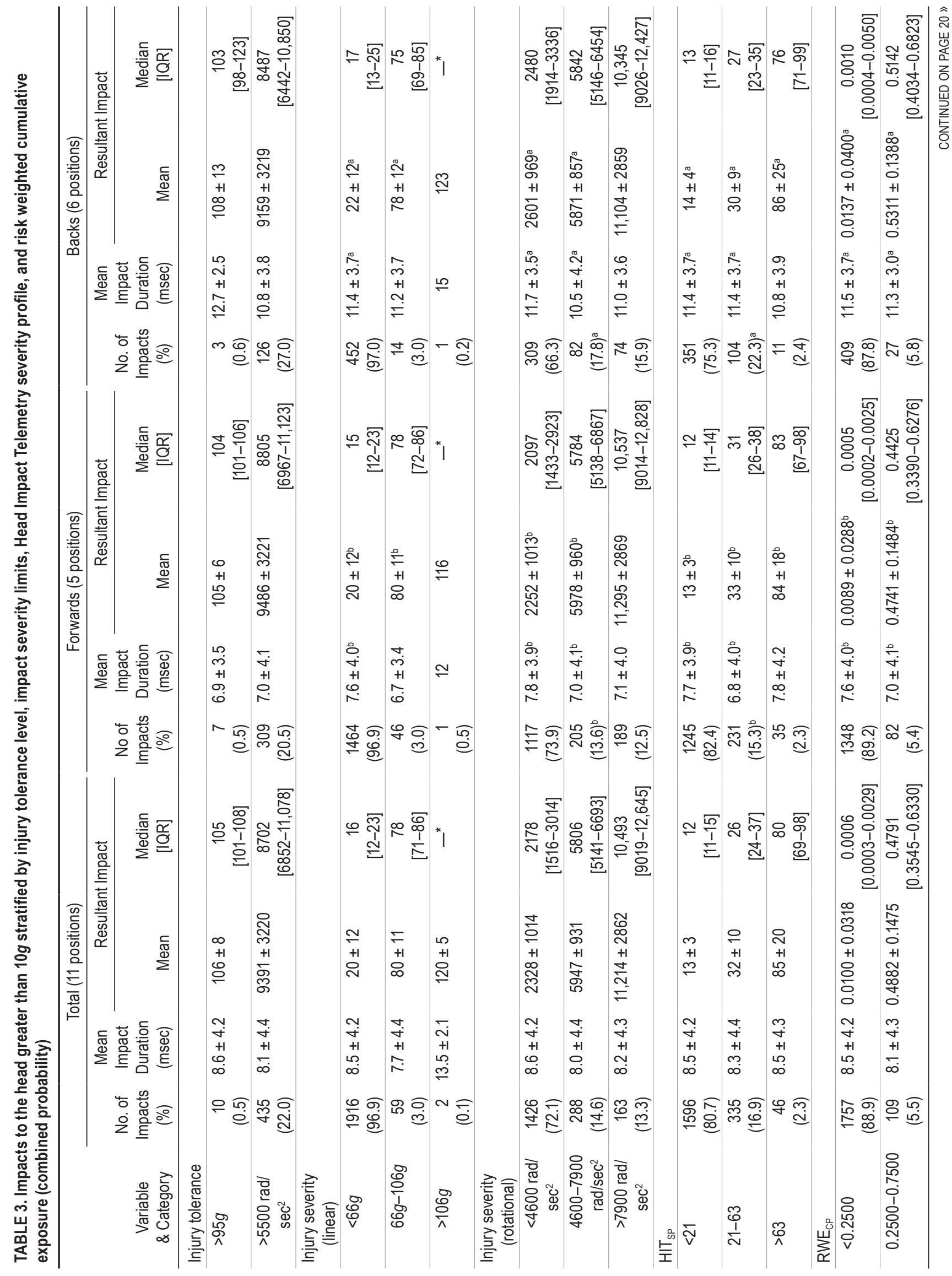




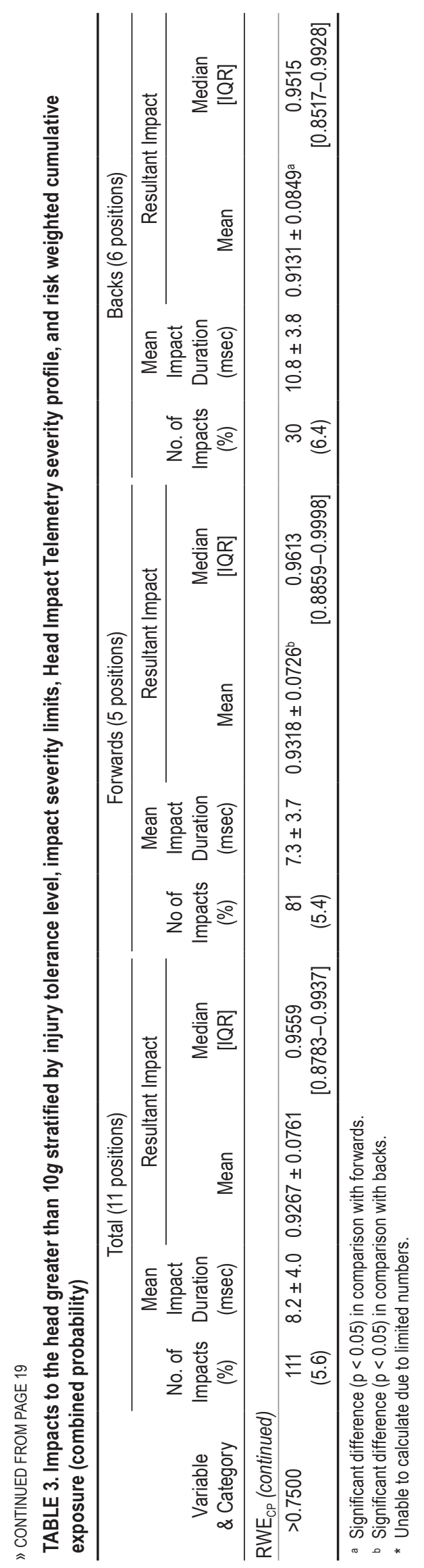

per match..$^{11}$ In players aged $12-14$ years, ${ }^{12}$ an average of 112 impacts were recorded per match or 12 impacts per player per match. These studies reported fewer impacts per match and per player per match than we found in our study (median 116 impacts per match or 13 impacts per player per match). Similar to other studies reporting head impact biomechanics, the majority of impact magnitudes recorded in our study (64\%) had a linear acceleration of between $10 \mathrm{~g}$ and $20 \mathrm{~g}$. Nevertheless, we did record some impacts $(\mathrm{n}=28)$ over $80 \mathrm{~g}$. This magnitude has been described as "high" 36 and it underscores that these young players, despite competing in youth league, can be exposed to impacts over a competition duration that can be considered high magnitude at any level of participation.

The median linear acceleration recorded in our study $(16 \mathrm{~g})$ was similar to that recorded in a study of 7- and 8 -year-old American football players. ${ }^{50}$ This result was higher than that recorded for 9- to 12-year-old players $(8 g)^{7}$ but lower than recorded for 12- to 14-year-old players $(22 g){ }^{12}$ Although the players in the current study may have had a lower resultant linear acceleration than American football players of similar ages, this variation may be reflective of how different the games of rugby league and American football are. Young American football players use full protective equipment, including rigid helmets and padding; in contrast, players in a junior rugby league are required to wear a fitted mouth guard and have the option to wear soft padded shoulder pads and head gear, but not all players do wear these optional protective equipment.

When comparing the median and 95th percentile peak resultant rotational accelerations recorded in our study (4041 rad/sec and 11,143 rad/ $/ \mathrm{sec}^{2}$, respectively), we found that the values were higher than those recorded for American football players who were 7-8 years old (median 686 $\mathrm{rad} / \mathrm{sec}^{2}, 95$ th percentile $\left.2052 \mathrm{rad} / \mathrm{sec}^{2}\right)^{50}$ or 12-14 years old (median $\left.987 \mathrm{rad} / \mathrm{sec}^{2}, 2769 \mathrm{rad} / \mathrm{sec}^{2}\right),{ }^{12}$ as well as for those playing at the high school level ${ }^{5,6}$ (median $903 \mathrm{rad} / \mathrm{sec}^{2}$, 95th percentile $2527 \mathrm{rad} / \mathrm{sec}^{2}$ ) and collegiate level ${ }^{10,43,44}$ (median 904-981 rad/ $/ \mathrm{sec}^{2}$, 95th percentile 2787-2975 rad/ $\mathrm{sec}^{2}$ ). Again, the differences observed in the peak resultant linear accelerations may be related to differences in the style of match participation in rugby league and American football in aspects such as tackle technique. As there are no other studies reporting on how the tackle techniques seen in rugby league differ from tackles in American football, where play ceases once the ball or the player carrying the ball is grounded, comparisons for this are unable to be undertaken. Further research is warranted to explore the differences in tackle techniques and how they may have an effect on the forces recorded by the head.

There is another possible explanation for the observed differences recorded in the current study. Comparison of children and adults has shown biomechanical differences in relationship to the head and neck. ${ }^{35}$ Also, children have less developed neck and shoulder musculature and an increased head-to-body ratio compared with adults..$^{40,47}$ As a result, children may have a higher center of gravity, and greater head momentum, than adults. ${ }^{47}$ A possible consequence of these differences in children may be that compared with adults, children are less able to dissipate impact forces that occur from match participation. Consequently, 
TABLE 4. Characteristics of participants

\begin{tabular}{lc}
\hline \multicolumn{1}{c}{ Characteristic } & Value \\
\hline No. of players enrolled & 19 \\
\hline Age in yrs, mean \pm SD & $10.4 \pm 0.9$ \\
\hline Matches played (no. of match hrs) & $12(88.0)$ \\
\hline No. of concussive incidents & 7 \\
\hline Witnessed & 0 \\
\hline Unwitnessed & 7 \\
\hline Preseason K-D Test 1, sec, median [IQR] & $62.2[59.0-74.9]$ \\
\hline Preseason K-D Test 2, sec, median [IQR] & $63.8[56.0-72.3]^{\mathrm{a}}$ \\
\hline Difference Test 1 vs Test 2, sec, median [IQR] & $-4.1[-8.0$ to -1.5$]$ \\
\hline Baseline K-D score, sec, median [IQR] & $62.1[56.0-71.3]$ \\
\hline Postseason K-D score, sec, median [IQR] & $51.4[47.0-62.6]^{\mathrm{b}}$ \\
\hline K-D score change pre- to postseason, sec, & $-8.0[-9.8$ to -2.2$]$ \\
median [IQR] & $0.92(0.79-0.97)$ \\
\hline ICC (95\% CI) for K-D score Baseline 1 vs & \\
\hline Baseline 2 & $0.92(0.80-0.97)$ \\
\hline ICC (95\% CI) for K-D score baseline vs \\
postseason
\end{tabular}

lesser forces may be required to cause similar concussive injuries in smaller brains than larger brains with greater mass. ${ }^{19,40}$ Therefore, the signs and symptoms of concussion in children may be the result of greater forces than if an adult presents with similar signs and symptoms of a concussive injury. ${ }^{35}$

By incorporating the RWE for linear, rotational, and combined probability, the variability of exposure due to linear and rotational accelerations can be identified. ${ }^{46}$ Only Urban et al ${ }^{46}$ have reported RWE in American football at the high school level (player age 14-18 years). They found a median value for rotational accelerations of $22 \mathrm{~g}$ and a 95th percentile value of $62 \mathrm{~g}$. The median rotational acceleration values reported were $1013 \mathrm{rad} / \mathrm{sec}^{2}$ and a 95th percentile of $2743 \mathrm{rad} / \mathrm{sec}^{2}$. The linear accelerations were similar to those found in the current study while the rotational accelerations were lower at the same data acquisition limit. Reviewing the results of the 2 studies by RWE shows that the median value for $\mathrm{RWE}_{\mathrm{CP}}$ was lower in our study than in theirs $\left(0.194^{46}\right.$ vs 0.001$)$. The differences seen here may be related to the regression coefficients used and the exposure time differences between the different sporting codes. The use of the RWE may be beneficial but may be limited to the same sporting code comparisons. Further research is warranted to identify whether there are differences between sporting codes and if the regression coefficients used are appropriate for nonhelmeted sporting activities.

\section{Limitations}

In the current study, we have reported the linear and rotational accelerations by the mean, median, and 95th percentile results recorded, and these data were used for comparisons with limited previous studies reporting on American Pop Warner, youth, and high school football. Other studies have used either a median and/or 95th percentile result format or only reported on linear accelerations, which has limited interstudy comparisons. This has resulted in the information provided by these studies being left to stand alone awaiting future studies reporting similar data acquisition limits and formats that enable comparisons.

The players in this study were between 9 and 11 years old, and the impact characteristics may be specific to this age group. The head impact exposure experienced by this cohort of players may differ from that of other junior rugby league players at different age group levels, just as the head impact exposure likely varies by age.

Although the XPatch has undergone some reported validation studies and has been compared with HITS, the results have varied. The accelerometers used in this study have been reported to have a strong correlation for anterior-posterior translation $\left(\mathrm{r}^{2}=0.93\right),{ }^{49}$ a normalized root square error of $18 \%$ for PLA, and an overprediction of $15 g \pm 7 g$ and $2500 \pm 1200 \mathrm{rad} / \mathrm{sec}^{2}$ for PRA. ${ }^{49}$ Nevins et al. ${ }^{38}$ reported that the XPatch had good estimates of PLA but underestimated PRA by more than $25 \%$ and recorded more impacts than were visibly seen. As a result of these different findings, the impact variables reported in this study should be assumed to have some form of error that is dependent on impact conditions, the measurement of interest, and the variability tested. ${ }^{5,23}$ It is unlikely that the XPatch (X2Biosystems) was tested under all of the conditions seen in rugby league matches and how these conditions would correlate with the laboratory conditions remains unknown. There are no consistent reliability studies for the XPatch and the resultant impact variables that are recorded; therefore the results presented in this study should be interpreted with some caution.

\section{Conclusions}

A total of 1977 impacts were recorded during the 2014 match competition season through the use of accelerometer-fitted patches worn behind the ear of participants in a single rugby league junior team. The mean linear acceleration was similar to mean linear accelerations reported in studies of American Pop Warner and youth football participants. The mean rotational accelerations were higher than those measured in studies of American Pop Warner, youth, and high school football players. Additional studies should investigate impacts at the senior and professional levels of participation as well as in female players. Standardization of reporting head impact biomechanics is needed in order to facilitate accurate comparisons between studies.

\section{Acknowledgments}

We wish to thank the players, and the parents of the players, who participated in the study. We also thank Jason Thibado, Ed Mlinek, Christoph Mac, and Rich Able from X2Biosystems for their provision of the XPatch and the head injury management software. 


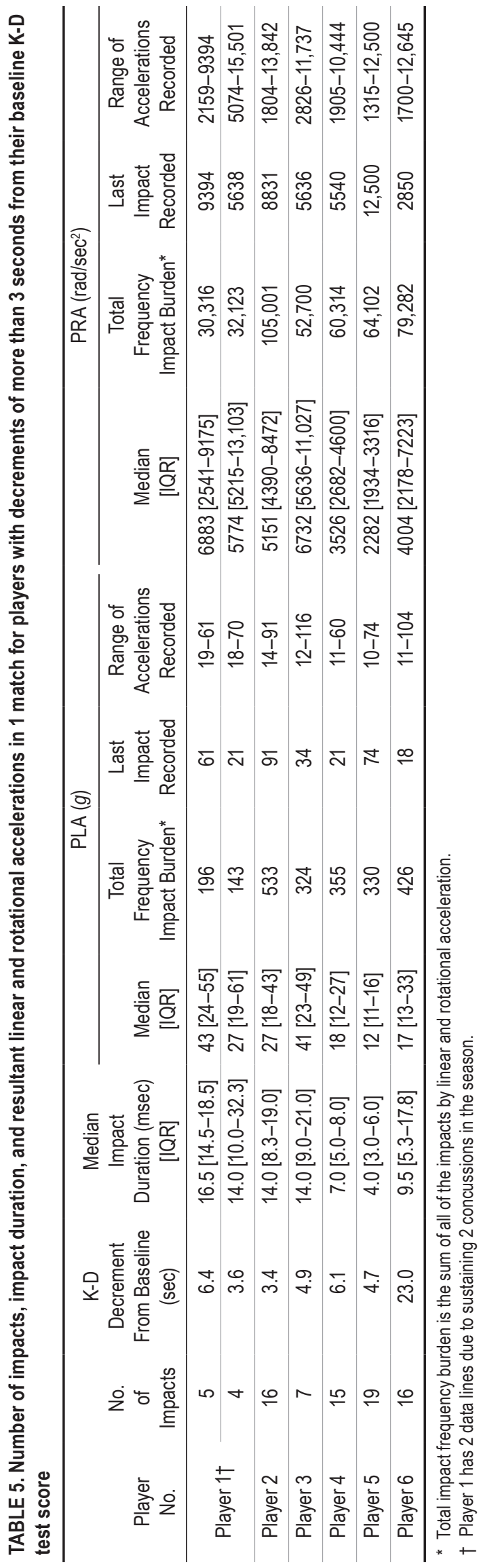

\section{References}

1. Altman DG, Bland JM: Diagnostic tests. 1: Sensitivity and specificity. BMJ 308:1552, 1994

2. Broglio SP, Eckner JT, Martini D, Sosnoff JJ, Kutcher JS, Randolph C: Cumulative head impact burden in high school football. J Neurotrauma 28:2069-2078, 2011

3. Broglio SP, Eckner JT, Surma T, Kutcher JS: Post-concussion cognitive declines and symptomatology are not related to concussion biomechanics in high school football players. J Neurotrauma 28:2061-2068, 2011

4. Broglio SP, Schnebel B, Sosnoff JJ, Shin S, Fend X, He X, et al: Biomechanical properties of concussions in high school football. Med Sci Sports Exerc 42:2064-2071, 2010

5. Broglio SP, Sosnoff JJ, Shin S, He X, Alcaraz C, Zimmerman J: Head impacts during high school football: a biomechanical assessment. J Athl Train 44:342-349, 2009

6. Broglio SP, Surma T, Ashton-Miller JA: High school and collegiate football athlete concussions: a biomechanical review. Ann Biomed Eng 40:37-46, 2012

7. Cobb BR, Urban JE, Davenport EM, Rowson S, Duma SM, Maldjian JA, et al: Head impact exposure in youth football: elementary school ages 9-12 years and the effect of practice structure. Ann Biomed Eng 41:2463-2473, 2013

8. Crisco JJ, Chu JJ, Greenwald RM: An algorithm for estimating acceleration magnitude and impact location using multiple nonorthogonal single-axis accelerometers. J Biomech Eng 126:849-854, 2004

9. Crisco JJ, Fiore R, Beckwith JG, Chu JJ, Brolinson PG, Duma S, et al: Frequency and location of head impact exposures in individual collegiate football players. J Athl Train 45:549-559, 2010

10. Crisco JJ, Wilcox BJ, Beckwith JG, Chu JJ, Duhaime AC, Rowson S, et al: Head impact exposure in collegiate football players. J Biomech 44:2673-2678, 2011

11. Daniel RW, Rowson S, Duma SM: Head impact exposure in youth football. Ann Biomed Eng 40:976-981, 2012

12. Daniel RW, Rowson S, Duma SM: Head impact exposure in youth football: middle school ages 12-14 years. J Biomech Eng 136:094501-094506, 2014

13. DeSouza JF, Menon RS, Everling S: Preparatory set associated with pro-saccades and anti-saccades in humans investigated with event-related FMRI. J Neurophysiol 89:1016-1023, 2003

14. Field M, Collins MW, Lovell MR, Maroon J: Does age play a role in recovery from sports-related concussion? A comparison of high school and collegiate athletes. J Pediatr 142:546-553, 2003

15. Gabbett T, Kelly J, Pezet T: A comparison of fitness and skill among playing positions in sub-elite rugby league players. J Sci Med Sport 11:585-592, 2008

16. Galetta KM, Barrett J, Allen M, Madda F, Delicata D, Tennant AT, et al: The King-Devick test as a determinant of head trauma and concussion in boxers and MMA fighters. Neurology 76:1456-1462, 2011

17. Galetta KM, Brandes LE, Maki K, Dziemianowicz MS, Laudano E, Allen M, et al: The King-Devick test and sportsrelated concussion: study of a rapid visual screening tool in a collegiate cohort. J Neurol Sci 309:34-39, 2011

18. Galetta MS, Galetta KM, McCrossin J, Wilson JA, Moster S, Galetta SL, et al: Saccades and memory: baseline associations of the King-Devick and SCAT2 SAC tests in professional ice hockey players. J Neurol Sci 328:28-31, 2013

19. Goldsmith W, Plunkett J: A biomechanical analysis of the causes of traumatic brain injury in infants and children. Am J Forensic Med Pathol 25:89-100, 2004

20. Greenwald RM, Gwin JT, Chu JJ, Crisco JJ: Head impact severity measures for evaluating mild traumatic brain injury risk exposure. Neurosurgery 62:789-798, 2008

21. Guskiewicz KM, Mihalik JP, Shankar V, Marshall SW, 
Crowell DH, Oliaro SM, et al: Measurement of head impacts in collegiate football players: relationship between head impact biomechanics and acute clinical outcome after concussion. Neurosurgery 61:1244-1253, 2007

22. Hanlon EM, Bir CA: Real-time head acceleration measurement in girls' youth soccer. Med Sci Sports Exerc 44:1102 1108,2012

23. Harpham JA, Mihalik JP, Littleton AC, Frank BS, Guskiewicz KM: The effect of visual and sensory performance on head impact biomechanics in college football players. Ann Biomed Eng 42:1-10, 2014

24. Hopkins WG, Marshall SW, Batterham AM, Hanin J: Progressive statistics for studies in sports medicine and exercise science. Med Sci Sports Exerc 41:3-13, 2009

25. Hopkins WG, Marshall SW, Quarrie KL, Hume PA: Risk factors and risk statistics for sports injuries. Clin J Sport Med 17:208-210, 2007

26. King D: Sports-Related Concussion in New Zealand Amateur Rugby Union and League: Identification, Assessment and Impact Forces Involved [dissertation]. Auckland: Auckland University of Technology, 2015, p 341

27. King D, Clark T, Gissane C: Use of a rapid visual screening tool for the assessment of concussion in amateur rugby league: a pilot study. J Neurol Sci 320:16-21, 2012

28. King D, Hume P, Gissane C, Clark T: Use of the King-Devick test for sideline concussion screening in junior rugby league. J Neurol Sci 357:75-79, 2015

29. King D, Hume PA, Brughelli M, Gissane C: Instrumented mouthguard acceleration analyses for head impacts in amateur rugby union players over a season of matches. Am J Sports Med 43:614-624, 2015

30. King DA, Hume PA, Gissane C, Clark TN: Similar head impact acceleration measured using instrumented ear patches in a junior rugby union team during matches in comparison with other sports. J Neurosurg Pediatr 18:65-72, 2016

31. Krause LM, Naughton GA, Denny G, Patton D, Hartwig T, Gabbett TJ: Understanding mismatches in body size, speed and power among adolescent rugby union players. J Sci Med Sport 18:358-363, 2015

32. Landis JR, Koch GG: The measurement of observer agreement for categorical data. Biometrics 33:159-174, 1977

33. Lennon A: Measurement of Head Impact Biomechanics: A Comparison of the Head Impact Telemetry System and X2Biosystems XPatch [dissertation]. Chapel Hill: University of North Carolina, 2015, p 44

34. Leong DF, Balcer LJ, Galetta SL, Liu Z, Master CL: The King-Devick test as a concussion screening tool administered by sports parents. J Sports Med Phys Fitness 54:70-77, 2014

35. Meehan WP III, Taylor AM, Proctor M: The pediatric athlete: younger athletes with sport-related concussion. Clin Sports Med 30:133-144, x, 2011

36. Mihalik JP, Bell DR, Marshall SW, Guskiewicz KM: Measurement of head impacts in collegiate football players: an investigation of positional and event-type differences. Neurosurgery 61:1229-1235, 2007

37. Mihalik JP, Blackburn JT, Greenwald RM, Cantu RC, Marshall SW, Guskiewicz KM: Collision type and player anticipation affect head impact severity among youth ice hockey players. Pediatrics 125:e1394-e1401, 2010

38. Nevins D, Smith L, Kensrud J: Laboratory evaluation of wireless head impact sensor. Procedia Eng 112:175-179, 2015

39. Ocwieja KE, Mihalik JP, Marshall SW, Schmidt JD, Trulock SC, Guskiewicz KM: The effect of play type and collision closing distance on head impact biomechanics. Ann Biomed Eng 40:90-96, 2012

40. Ommaya AK, Goldsmith W, Thibault L: Biomechanics and neuropathology of adult and paediatric head injury. Br J Neurosurg 16:220-242, 2002

41. Pellman EJ, Viano DC, Tucker AM, Casson IR, Waeckerle JF: Concussion in professional football: reconstruction of game impacts and injuries. Neurosurgery 53:799-814, 2003

42. Rizzo JR, Hudson TE, Dai W, Desai N, Yousefi A, Palsana D, et al: Objectifying eye movements during rapid number naming: Methodology for assessment of normative data for the King-Devick test. J Neurol Sci 362:232-239, 2016

43. Rowson S, Duma SM: Development of the STAR evaluation system for football helmets: integrating player head impact exposure and risk of concussion. Ann Biomed Eng 39:21302140,2011

44. Rowson S, Duma SM, Beckwith JG, Chu JJ, Greenwald RM, Crisco JJ, et al: Rotational head kinematics in football impacts: an injury risk function for concussion. Ann Biomed Eng 40:1-13, 2012

45. Tjarks BJ, Dorman JC, Valentine VD, Munce TA, Thompson PA, Kindt SL, et al: Comparison and utility of King-Devick and ImPACT ${ }^{\circledR}$ composite scores in adolescent concussion patients. J Neurol Sci 334:148-153, 2013

46. Urban JE, Davenport EM, Golman AJ, Maldjian JA, Whitlow CT, Powers AK, et al: Head impact exposure in youth football: high school ages 14 to 18 years and cumulative impact analysis. Ann Biomed Eng 41:2474-2487, 2013

47. Vopat LM, Micheli LJ: Emergency care of the adolescent athlete, in McDonagh D, Zideman D (eds): The IOC Manual of Emergency Sports Medicine. West Sussex, UK: Wiley Blackwell, 2015, pp 205-211

48. Wong RH, Wong AK, Bailes JE: Frequency, magnitude, and distribution of head impacts in Pop Warner football: the cumulative burden. Clin Neurol Neurosurg 118:1-4, 2014

49. Wu L, Nangia V, Bui K, Hammoor B, Kurt M, Hernandez F, et al: In vivo evaluation of wearable head impact sensors. Ann Biomed Eng 44:1234-1245, 2016

50. Young TJ, Daniel RW, Rowson S, Duma SM: Head impact exposure in youth football: elementary school ages 7-8 years and the effect of returning players. Clin J Sport Med 24:416-421, 2014

51. Zhang L, Yang KH, King AI: A proposed injury threshold for mild traumatic brain injury. J Biomech Eng 126:226236,2004

\section{Disclosures}

The XPatch impact-sensing skin patches and the head injury management software used in this study were provided by X2Biosystems Ltd.

\section{Author Contributions}

Conception and design: King, Hume, Clark. Acquisition of data: King. Analysis and interpretation of data: all authors. Drafting the article: King. Critically revising the article: all authors. Reviewed submitted version of manuscript: King. Approved the final version of the manuscript on behalf of all authors: King. Statistical analysis: King, Gissane.

\section{Correspondence}

Doug King, Emergency Department, Hutt Valley District Health Board, Private Bag 31-907, Lower Hutt 5040, New Zealand. email: doug.king@clear.net.nz. 